Quality : Jurnal Kesehatan

Volume 15, Nomor 2 Tahun 2021

pISSN : 1978-4325, eISSN : 2655-2434, DOI: 10.36082/qjk.v15i2.274

\title{
EFEKTIVITAS TEKNIK JARIK SHAKING THE APPLE TREE TERHADAP PERSEPSI NYERI PADA IBU BERSALIN \\ Heni Mahita $^{1}$, Yusniarita ${ }^{1}$, Yossy Utario ${ }^{2}$ \\ ${ }^{1}$ Jurusan Kebidanan, Politeknik Kesehatan Kemenkes Bengkulu, Indonesia \\ ${ }^{2}$ Jurusan Keperawatan, Politeknik Kesehatan Kemenkes Bengkulu, Indonesia
}

\begin{tabular}{ll}
\hline Info Artikel & Abstrak \\
\hline Genesis Naskah: & $\begin{array}{l}\text { Ibu bersalin berespon terhadap nyerinya dengan cara yang berbeda-beda. Beberapa ibu mungkin } \\
\text { merasa takut dan cemas sementara yang lain nya bersifat toleran dan optimis. Salah satu metode } \\
\text { non farmakologi untuk pengendalian rasa nyeri yaitu teknik jarik shaking the apple tree, teknik }\end{array}$ \\
$\begin{array}{l}\text { Submission:9-05-2021 } \\
\text { Revised:10-10-2021 }\end{array}$ & $\begin{array}{l}\text { ini berperan dalam merileksasi otot-otot panggul sehingga memberikan rasa nyaman saat } \\
\text { persalinan. Tujuan penelitian ini untuk mengetahui efektivitas teknik jarik shaking the apple tree }\end{array}$ \\
& $\begin{array}{l}\text { terhadap persepsi nyeri pada ibu bersalin kala 1 fase aktif di wilayah kerja Puskesmas Pasar } \\
\text { Kepahiang. Jenis penelitian ini menggunakan rancangan praexperimental design dengan jenis } \\
\text { pre test and post test one group design. Pengambilan sampel menggunakan teknik total sampling } \\
\text { Kata Kunci: }\end{array}$ \\
$\begin{array}{l}\text { Tekngan jumlah ibu bersalin sebanyak 22 sampel. Skala nyeri dinilai dengan dengan lembar } \\
\text { observasi Numeric Rating Scale (NRS ) dan persepsi nyeri dengan lembar kuisioner serta dengan }\end{array}$ \\
Apple Tree, nyeri & wawancara individu. Uji statistik yang digunakan uji Wilcoxon signed ranks test. Hasil: teknik \\
persalinan, Persepsi Nyeri & jarik efektif terhadap penurunan skala nyeri pada ibu bersalin, dengan nilai p 0,000(<0,005), dan \\
& Metode jarik shake the apple tree efektif dalam peningkatan persepsi nyeri persalinan sebelum \\
dan sesudah intervensi, dengan nilai p 0.000 (<0.05). Saran bagi ibu yang akan bersalin dapat & menggunakan metode jarik shake the apple tree sebagai penanganan nyeri persalinan.
\end{tabular}

\section{THE EFFECTIVENESS OF JARIK SHAKING THE APPLE TREE TECHNIQUES TOWARD PAIN PERCEPTION IN LABOR MOTHER}

Keywords:

Jarik Shaking the Apple

Tree Technique, Labor pain,

Pain perception

\begin{abstract}
Mothers in labor responds to pain in different ways. Some mothers may feel fear and anxious while others are tolerant and optimistic. One of the non-pharmacological methods for pain control is jarik shake the apple tree technique, this technique plays a role in relaxing the pelvic muscles to provide a comfortable feeling during labor. The purpose of this study was to determine the effectiveness of jarik shaking the apple tree technique against pain perception in labor mother when there was one phase happen actively in the working area of Community Health Center Pasar Kepahiang. This type of research used are pre-experimental design with the type of pre-test and post-test one group design. This research used a total sampling technique with the number of giving birth mothers as many as 22 samples. The pain scale was assessed by using the Numeric Rating Scale (NRS) observation sheet and pain perception with questionnaire sheet as well as with individual interviews. The statistical test was the Wilcoxon signed ranks test. Result: jarik technique was effective in decreasing the pain scale in labor mother, with a $\mathrm{p}$ value of 0.000 $(<0.005)$, and jarik shake the apple tree method was effective in improving the perception of labor pain before and after the intervention, with a p value of $0.000(<0.05)$. Suggesting this technique jarik shaking the apple tree for the mothers who are going to giving birth as a treatment for labor pain.
\end{abstract}

Korespondensi Penulis:

Yusniarita

Jl. Sapta Marga No. 95 Desa Teladan Kec. Curup selatan Kab. Rejang Lebong, Indonesia

Email: yt28sakura@gmail.com 


\section{Pendahuluan}

Nyeri persalinan merupakan proses fisiologis, ibu-ibu yang bersalin berespon terhadap nyerinya dengan cara yang berbeda-beda (Maryunani, 2010). Manajemen nyeri persalinan telah diupayakan secara nonfarmakologis yaitu teknik relaksasi, Akupresure, Aromatherapy dan massage. Salah satu teknik relaksasi untuk pengendalian rasa nyeri non farmakologi dalam proses persalinan adalah menggunakan teknik rebozo. Relaksasi bukan hanya aktivitas pasif tapi aktif. Melakukan teknik relaksasi dapat melepaskan ketegangan otot, mengurangi ketegangan fisik dan mengurangi nyeri. Sehingga membuat rasa aman, nyaman dan akhirnya akan mengurangi kecemasan serta mengurangi kepekaan terhadap rasa nyeri (Cohen, Susanna \& Thomas, Celeste. 2015).

Menurut (Iversen, Midtgaard, Ekelin, \& Hegaard, 2017), Teknik rebozo berasal dari Amerika Latin, rebozo adalah kain panjang yang biasa dipakai wanita Meksiko untuk melakukan kegiatan sehari-hari. Kain ini dapat digunakan untuk membantu pasangan memberikan rasa nyaman selama menjelang proses persalinan dengan teknik yang dapat dipelajari bersama pasangan. Metode jarik shaking the apple tree sebagai bagian dari teknik rebozo memiliki tujuan merelaksasikan otot-otot bagian panggul dan bokong. Metode ini dapat digunakan saat kontraksi dan antara kontraksi. Penggunaan rebozo atau jarik memberikan sensasi seperti pijatan pada punggung dan perut mereka. Kenyamanan yang muncul dengan menggoyangkan selendang pada daerah pinggul ini juga membuat otot pinggul mereka terasa rileks dan nyaman.

Berdasarkan penelitian., Iversen, et all (2017) tentang teknik rebozo untuk mengatasi malposisi janin berjumlah 7 responden, PROM berjumlah 3 responden, penurunan janin berjumlah 3 responden, pereda nyeri berjumlah 1 responden, dan memperkuat kontraksi 2 responden. Teknik rebozo dapat dilakukan dengan posisi berdiri, tangan dan lutut, serta berbaring. Beberapa hasil penelitian menyatakan bahwa pengalaman para wanita yang mengalami nyeri saat kontraksi dalam persalinan dilakukan

(C) Poltekkes Kemenkes Jakarta I

J1. Wijaya Kusuma No. 47-48 Cilandak Jakarta Selatan, Indonesia email: jurnalquality@poltekkesjakarta1.ac.id dengan teknik rebozo untuk mengatasi nyeri secara keseluruhan sangat positif, salah satunya meningkatkan rasa kenyamanan selama persalinan. Berdasarkan penelitian Rusniati et al., (2017) bahwa pada ibu bersalin multigravida dengan lamanya persalinan kala I sebanyak 18 responden $(51,4 \%)$ dengan lamanya persalinan 9 jam. Sedangkan lama persalinan pada kala II sebanyak 29 orang $(82,9 \%)$ dengan lamanya persalinan 61-100 menit.

Persalinan yang di tolong oleh tenaga kesehatan di Kabupaten Kepahiang Tahun 2018 berjumlah 2.211 dari jumlah ibu bersalin sebanyak $2.643(83,7 \%)$. Cakupan pertolongan persalinan oleh tenaga kesehatan tertinggi di Wilayah Kerja Puskesmas Ujan Mas yaitu sebesar 95,8\% dan cakupan terendah di wilayah kerja Puskesmas Embong Ijuk (69,6\%), Puskesmas Pasar Kepahiang menduduki urutan ke 5 dengan persentase 90,9\% dari 14 puskesmas yang ada di Kabupaten Kepahiang (Profile Kesehatan Kabupaten Kepahiang , 2018).

Tujuan penelitian ini adalah untuk mengetahui efektivitas teknik jarik shaking the apple tree terhadap persepsi nyeri pada ibu bersalin kala I fase aktif di wilayah kerja Puskesmas Pasar Kepahiang.

\section{Metode}

Penelitian ini menggunakan rancangan pra experimental design, pre test and post test one group design. Populasi dalam penelitian ini yaitu semua ibu bersalin yang memenuhi kriteria inklusi diwilayah kerja Puskesmas Pasar Kepahiang bulan Februari tahun 2020. Sampel sebanyak 22 ibu bersalin kala I fase aktif sebagai responden. Teknik sampel menggunakan total sampling.

Teknik melakukan Metode jarik shaking the apple tree intervensi di lakukan saat pasien mulai mengalami kontraksi dengan pembukaan 4 $\mathrm{cm}$ dengan cara atur posisi ibu seperti merangkak, atau semi tengkurap. Selanjutnya pasang kain jarik dengan menutupi seluruh pinggul Ibu, petugas memegang sisi jarik dengan kedua tangan. Jarik digerakkan atau diayunkan kekiri dan kekanan, gerakan seperti massage. dengan memberikan tekanan dan guncangan pada pinggul Teknik intervensi ini dilakukan setiap kontraksi sampai dengan pembukaan lengkap.

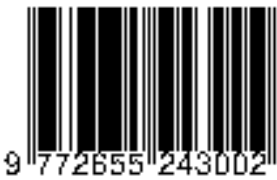


Intervensi jarik shaking the apple tree dilakukan sampai pasen merasa relaksasi atau terus sampai nyeri berkurang. Penilaian persepsi nyeri dilakukan sebelum dan setelah intervensi dengan mengisi kuisioner dan lembar observasi numeric rating scale (NRS).

Instrumen penelitian menggunakan lembar kuesioner persepsi nyeri yang dimodifikasi dari peneliti terdahulu yaitu yaitu Ziba Taghizdeh, (2018) uji validitas yaitu nilai $r$ tabel 0,514 dan nilai reabilitas > 0.6 maka item pertanyaan hasil nya valid dan realiabel dengan nilai cronbach alpha $r$ 0,977, Instrumen lembar observasi skala nyeri dengan skala Numeric Rating Scale (NRS) dan wawancara Responden.

Data dikumpulkan dari hasil kuesioner persepsi nyeri dan skala nyeri ibu bersalin kala I fase aktif. Data univariat dianalisis untuk mengetahui frekuansi skala nyeri dan persepsi nyeri, selanjutnya data bivariat menggunakan uji Wilcoxon signed ranks test, untuk mengetahui efektivitas teknik jarik shaking the apple tree terhadap persepsi nyeri pada ibu bersalin kala I fase aktif.

Penelitian ini telah medapatkan persetujuan layak etik dari Komite Etik Penelitian Kesehatan Poltekkes Kemenkes Bengkulu dengan nomor etik: KEPK.M/238/02/2020.

\section{Hasil}

Gambaran umum responden ibu bersalin kala I fase aktif berdasarkan analisa univariat, sebagai berikut:

Diagram 1. Distribusi Frekuensi Umur Ibu Bersalin Kala I Fase Aktif

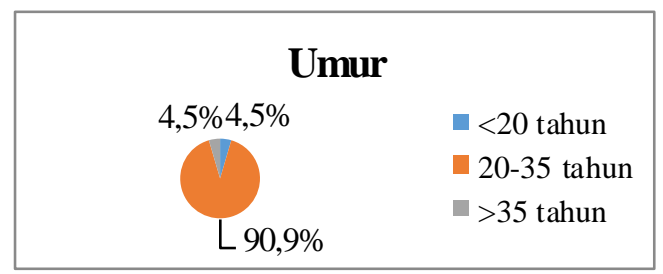

Pada diagram 1 menunjukkan hampir seluruh responden $90,9 \%$ berusia 20-35 tahun
Diagram 2.Distribusi Frekuensi Paritas Ibu Bersalin Kala I Fase Aktif

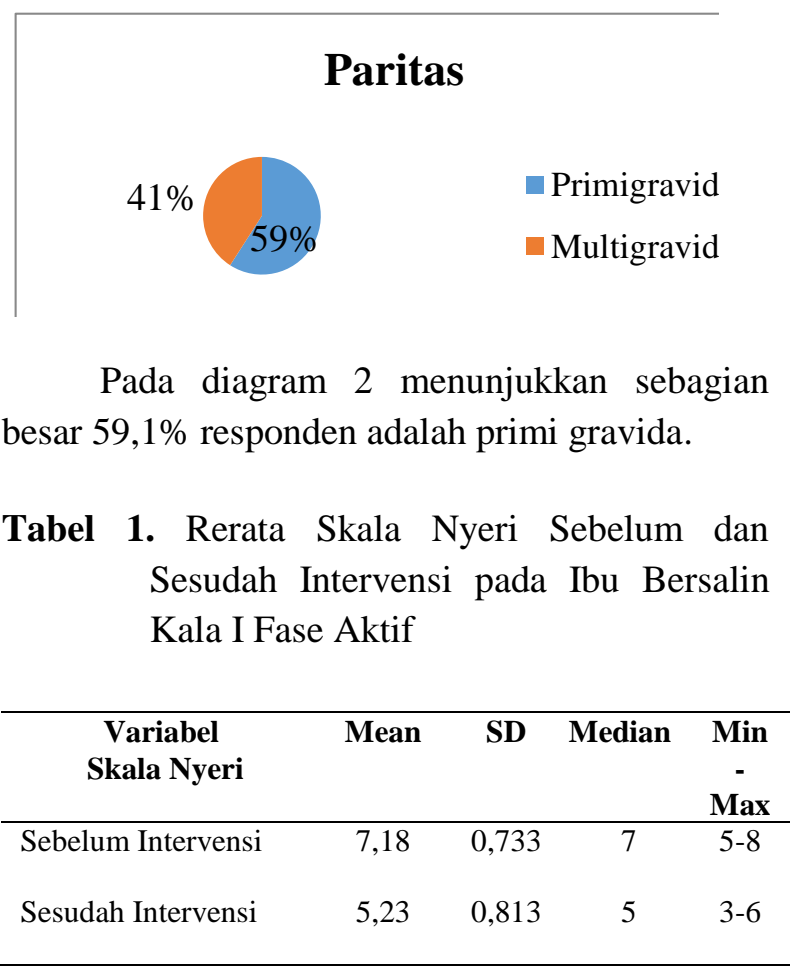

Berdasarkan tabel 1 nilai mean sebelum intervensi adalah 7,18 sedangkan sesudah dilakukan intervensi angka nilai mean skala nyeri 5,23 dengan selisih mean 1,95.

Tabel 2.Persepsi Nyeri Bersalin Sebelum dan Sesudah Intervensi

\begin{tabular}{lcccc}
\hline $\begin{array}{l}\text { Persepsi } \\
\text { Nyeri }\end{array}$ & Mean & SD & Median & $\begin{array}{c}\text { Min- } \\
\text { Max }\end{array}$ \\
\hline $\begin{array}{l}\text { Sebelum } \\
\begin{array}{l}\text { Intervensi } \\
\text { Sesudah } \\
\text { Intervensi }\end{array}\end{array}$ & 93,68 & 4,824 & 93,50 & $81-103$ \\
\hline
\end{tabular}

Berdasarkan tabel 2 nilai mean sebelum intervensi adalah 93,68 sedangkan sesudah dilakukan intervensi nilai mean persepsi nyeri 101,45 dengan selisih mean 7,77.

Selanjutnya dilakukan analisa bivariate, menggunakan uji Wilcoxon signed ranks test sebagai berikut: 
Tabel 3. Efektivitas Rerata Perubahan Skala Nyeri Sebelum dan Sesudah Intervensi Jarik shake the apple tree

\begin{tabular}{lcccccc}
\hline $\begin{array}{l}\text { Variabel } \\
\begin{array}{c}\text { Skala } \\
\text { Nyeri }\end{array}\end{array}$ & Mean & SD & Median & $\begin{array}{c}\text { Min- } \\
\text { Max }\end{array}$ & $\begin{array}{c}\text { Beda } \\
\text { mean }\end{array}$ & $\boldsymbol{p}^{*}$ \\
\hline $\begin{array}{l}\text { Sebelum } \\
\text { Intervensi }\end{array}$ & 7,18 & 0,733 & 7 & $5-8$ & & \\
$\begin{array}{l}\text { Sesudah } \\
\text { Intervensi }\end{array}$ & 5,23 & 0,813 & 5 & $3-6$ & 1.95 & 0.000 \\
\hline
\end{tabular}

*Uji Wilcoxon Signed Rank Test

Berdasarkan tabel 3 hasil uji analisis sebelum dan sesudah intervensi didapatkan nilai selisih mean 1,95 dan nilai $\mathrm{p}<0.05$ sehingga dapat disimpulkan bahwa teknik jarik shaking the apple tree efektif terhadap penurunan skala nyeri ibu bersalin kala I fase aktif di wilayah kerja Puskesmas Pasar kepahiang.

Tabel 4. Efektivitas Rerata Perubahan Persepsi Nyeri Sebelum dan Sesudah Intervensi Jarik shaking the apple tree

\begin{tabular}{llcccc}
\hline $\begin{array}{c}\text { Variabel } \\
\text { Persepsi } \\
\text { Nyeri }\end{array}$ & Mean & SD & Median & $\begin{array}{c}\text { Min- } \\
\text { Max }\end{array}$ & $\begin{array}{c}\text { Beda } \\
\text { mean }\end{array}$ \\
\hline $\begin{array}{l}\text { Sebelum } \\
\text { Intervensi }\end{array}$ & 93,68 & 4,824 & 93,50 & $81-$ & \\
Sesudah & 101,45 & 6,696 & 104,00 & $88-$ & 7.77 \\
Intervensi & & & & 110 & \\
& & & & &
\end{tabular}

*Uji Wilcoxon Signed Rank Test

Berdasarkan tabel 4 hasil uji analisis sebelum dan sesudah intervensi didapatkan nilai selisih mean 7.77 dan nilai $p<0.05$ sehingga dapat disimpulkan bahwa teknik jarik shaking the apple tree efektif terhadap peningkatan persepsi nyeri pada ibu bersalin kala I di wilayah kerja puskesmas pasar kepahiang.

Tabel 2. Persepsi Pengetahuan Tentang Nyeri Bersalin Sebelum dan Sesudah Intervensi pada Ibu Bersalin Kala I Fase Aktif di Wilayah Kerja Puskesmas Pasar Kepahiang Tahun 2020

\begin{tabular}{lccc}
\hline $\begin{array}{c}\text { Persepsi Pengetahuan } \\
\text { Nyeri Bersalin }\end{array}$ & Mean & SD & Median \\
\hline Sebelum Intervensi & 93,68 & 4,824 & 93,50 \\
Sesudah Intervensi & 101,45 & 6,696 & 104,00
\end{tabular}

(C) Poltekkes Kemenkes Jakarta I

Jl. Wijaya Kusuma No. 47-48 Cilandak Jakarta Selatan, Indonesia email: jurnalquality@poltekkesjakarta1.ac.id
Berdasarkan tabel 2 nilai mean sebelum intervensi adalah 93,68 sedangkan sesudah dilakukan intervensi nilai mean persepsi nyeri 101,45 dengan selisih mean 7,77.

\section{Pembahasan}

Hasil penelitian ini terdapat efektifitas teknik jarik shaking the apple tree efektif terhadap persepsi nyeri bersalin kala 1 fase aktif di wilayah kerja Puskesmas Pasar Kepahiang nilai $\mathrm{p}<0.05$.

Nyeri persalinan terjadi karena adanya regangan segmen bawah rahim, Intensitas nyeri sebanding dengan kekuatan kontraksi dan tekanan yang terjadi, nyeri bertambah ketika mulut rahim dalam dilatasi penuh akibat tekanan bayi terhadap struktur panggul. Nyeri persalinan unik dan berbeda pada setiap individu karena nyeri tidak hanya dikaitkan dengan kondisi fisik semata, tetapi berkaitan juga dengan kondisi psikologis ibu, dan pengalaman ibu pada saat persalinan.

Pada penelitian ini dari 22 responden memiliki persepsi nyeri yang berbeda-beda, ada yang menyatakan persepsi nyeri bersalin dengan skala rendah, sedang dan tinggi, sebelum dilakukan jutervensi teknik jarik shaking the apple tree. Gambaran rasa nyeri yang dirasakan ibu bersalin kala I sebelum dilakukan teknik jarik shaking the apple responden merasakan nyeri menahan rasa 0 @alit, menangis, berteriak secara umum tidak bisa mengantisipasi rasa nyeri persalinan. Setelah di lakukan teknik jarik shaking the apple tree sebagian besar ibu $(81,8 \%)$ rileks saat menghadapi nyeri atau kontraksi, merasakan nyaman, dan dapat mengatur nafas dengan baik dan nyeri yang dirasakan dapat teralihkan. Responden merasakan perubahan skala nyeri yang makin menurun dan pasen merasakan relaksasi setelah dilakukan tindakan teknik jarik shaking the apple tree. Teknik ini memberikan gambaran yang dapat mendistraksi atau memberikan pengalihan atau merelaksasi ligamen otot panggul.

Nyeri persalinan yang di rasakan ibu dinilai oleh skala nyeri VAS berada pada level 7,0 dan semakin berat dengan maju nya per\$lin Maßebagian besar ibu bersalin $(86,4 \%)$ menginginkan metode penghilang rasa nyeri persalinan (Akadri AA, 2018). Sejalan dengan penefitidn $^{3}$ (Sheela B, et al., 2018) yang mengungkapkan bahwa teknik rebozo efektif dalam mengurangi tingkat rasa nyeri selama

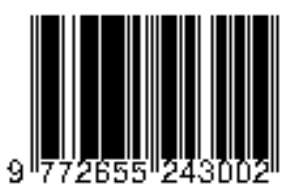


menstruasi di kalangan mahasiswa. Dengan menempatkan rebozo di sekitar punggung bawah dan bokong serta menggoyangkan rebozo dari sisi ke sisi dengan gerakan berirama akan memberikan relaksasi pada otot-otot panggul.

Hasil uji analisis sebelum dan sesudah intervensi didapatkan nilai nyeri dengan selisih mean 7,77 dan nilai p $0.000(<0.05)$. Dari hasil analisa dapat di simpulkan bahwa teknik jarik shaking the apple tree efektif terhadap peningkatan persepsi nyeri pada ibu bersalin kala I di wilayah kerja puskesmas pasar kepahiang.

Hasil penelitian ini sejalan dengan penelitian (Nurpratiwi, Hadi , \& Idriani, 2020) Berdasarkan hasil analisis dependent sample t-test menunjukkan nilai signifikan 2-tailed $<0,05$, maka terdapat perbedaan signifikan antara pre dan post pada intervensi teknik rebozo shaking the apple tree maupun teknik rebozo sifting while lying down. Rebozo merupakan kain selendang/jarik yang dipasang di panggul ibu bersalin, dengan gerakan terkontrol untuk membantu menggerakkan pinggul atau sedikit mengayunkannya dari sisi ke sisi. Gerakan ini yang memberikan tekanan dengan cara goyang atau goncangan di bagian panggul secara terusmenerus selama kontraksi, dimana penekanan tersebut tepatnya diletakkan pada tulang lumbal, sakrum dan koksigis (Lumbosacral) pasien dengan kain rebozo. Mekanisme rebozo shaking the apple tree inilah yang dapat membantu mengalihkan nyeri persalinan.

Secara teori saat ibu merasakan nyeri bersalin atau kontraksi apabila dilakukan massage dan penekanan di daerah lumbosacral ni dimana saraf sensorik rahim dan mulut rahim berjalan bersama saraf simpatis rahim memasuki sumsum tulang belakang melalui saraf torakal 10, 11, 12 sampai lumbal 1 , impuls nyeri ini dapat diblok dengan memberikan rangsangan pada saraf yang berdiameter besar dengan teknik rebozo shaking the apple tree atau rebozo sifting while lying down., sehingga impuls nyeri berjalan dari uterus sepanjang serabut saraf c-fiber menuju ke subtansia gelatinosa di dalam spinal colum, lalu sel-sel tersebut memproyeksikan pesan nyeri yang berlawanan sepanjang serat-serat saraf $a$ delta fibers yang menyebabkan gate control akan tertutup dan rangsangan nyeri tidak dapat diteruskan ke korteks serebral, maka persepsi di otak nyeri menjadi berkurang karena adanya

(C) Poltekkes Kemenkes Jakarta I

J1. Wijaya Kusuma No. 47-48 Cilandak Jakarta Selatan, Indonesia email: jurnalquality@poltekkesjakarta1.ac.id mekanoreseptor serabut beta-A akan menutup mekanisme pertahanan nyeri (Potter, 2005).

Salah satu cara untuk manajemen nyeri non farmakologi dilakukan tindakan teknik jarik shaking atau rebozo. Mekanisme kerja rebozo dapat merelaksasi otot-otot panggul yang tegang selama persalinan sehingga memberikan efek relaksasi pada proses persalinan. Berdasarkan Teori gate control dari (Potter, 2005) menyatakan bahwa impuls nyeri dapat diatur atau dihambat oleh mekanisme pertahanan di sepanjang sistem saraf pusat dengan menghantarkan impuls nyeri saat sebuah pertahanan dibuka dan impuls dihambat saat sebuah pertahanan tertutup.

Berdasarkan pengalaman di lapangan bahawa, setiap ibu bersalin mempunyai persepsi sendiri mengenai apa yang dipikirkan, dilihat, dan dirasakan. Ada beberapa factor yang mempengaruhi persepsi ibu terhadap nyeri bersalin, diantaranya usia ibu yang masih muda, pengalaman melahirkan yang lalu, budaya, psikologis ibu, dukungan keluarga, dan dukungan pendamping persalinan. Hal tersebut sekaligus berarti bahwa persepsi menentukan apa yang akan di perbuat seseorang unutuk memenuhi berbagai kepentingan baik untuk diri sendiri, keluarga, maupun lingkungan tempat berinteraksi. Persepsi inilah yang membedakan seseorang dengan yang lain. Persepsi dihasilkan dari kongkritisasi pemikiran, kemudian melahirkan konsep atau ide yang berbeda-beda dari masing-masing orang meskipun obyek yang dilihat sama.

Rasa nyeri selama proses persalinan mengakibatkan pengeluaran adrenalin yang akan mengakibatkan pembuluh darah berkontraksi sehingga akan mengurangi aliran darah yang membawa oksigen ke uterus dan mengakibatkan penurunan kontraksi uterus yang bisa menyebabkan memanjangnya waktu persalinan, sehingga menghilangkan rasa takut dan nyeri menjadi hal yang cukup penting (Indrayani, 2016).

Hasil penelitian (Aziato \& Umoar, K. L, 2017) selama proses persalinan wanita mengalami rasa nyeri yang dinilai ringan, sedang dan berat, rasa sakit itu terasa di daerah pinggang, vagina, perut bagian bawah dan tubuh secara umum. Para wanita mempresentasikan nyeri persalinan dengan menangis, menjerit dan berteriak dan beberapa wanita menahan rasa sakit, menangis dalam hati dan yang lain nya tidak menunjukan tanda-tanda rasa sakit.

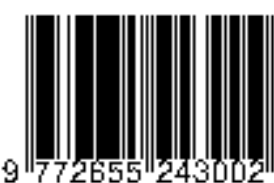


Langkah-langkah non farmakologis yang digunakan termasuk berjalan di sekitar, bernapas dalam-dalam, berbaring miring, memegang pinggang, jongkok, mandi dan mengunyah permen karet. Individualitas pengalaman dan ekspresi rasa sakit ditekankan pada orientasi sosial budaya wanita membuat beberapa wanita menjadi tabah.

Sejalan dengan penelitian (Mousa, Abdelhafez, Abdelraheim, \& Yousef, 2018) menyatakan bahwa nyeri persalinan yang dialami oleh ibu bersalin dipengaruhi oleh social budaya, pengalaman dan latihan, untuk itu petugas kesehatan yang menolong persalinan dapat menggunakan berbagai metode agar ibu dapat beradapatasi dengan nyeri selama proses perslainan. Manajeman mengatasi nyeri harus dilakukan dengan nyaman dan mempertimbangkan keselamatan ibu.

Setelah dilakukan intervensi teknik jarik rebozo shaking the apple tree didapatkan hampir seluruh responden menyatakan merasa nyeri kontraksi berkuran, pasien merasa rileks, merasa nyaman dan dapat mengatur napas dan juga lebih siap mengalami proses persalinan normal dimana saat proses melahirkan kekuatan yang didapat adalah sebagian proses yang alamiah, informasi yang didapat tentang proses melahirkan secara normalpun dapat diakses dari mana saja sehingga pemulihan pada persalinan normal nantinya juga akan lebih cepat dibandingkan dengan proses melahirkan secara section caesaria.

Pendamping persalinan juga mempengaruhi tingkat stress responden dan sebagian besar responden ingin didampingi oleh suami dan keluarganya, sehingga dukungan mental dan motivasi secara religius yang diberikan dapat memicu mental untuk bertahan menghadapi rasa nyeri. Dalam penelitian ini keluarga sebagai pendamping persalinan dilibatkan untuk melakukan teknik jarik shaking apple the tree. Hal ini didukung dengan hasil wawancara dengan responden dimana setelah di lakukan teknik jarik, responden mengatakan lebih memahami dan mengerti tentang konsep nyeri yang di alami. Sehingga responden lebih menerima rasa nyeri yang ia alami.

Pendamping persalinan dari petugas kesehatan dapat memberikan dukungan dengan memberikan latihan posisi persalinan dan latihan panggul. Latihan yang diberikan bisa dengan senam hamil, latihan pernapasan, menari, latihan kaki, birth ball, dan rebozo untuk mengatasi ketidaknyaman selama persalinan (Shilling, Romana, \& Difranco, 2007).

Teknik jarik shaking the apple tree efektif dalam pengelolaan dan pengendalian manajemen nyeri pada ibu bersalin dikarenakan tekanan dan goyangan pada pinggul dapat merileksasikan otot-otot bagian panggul dan bokong sehingga dapat meningkatkan produksi hormon endhorpin, mampu menurunkan nyeri responden dapat teralihkan terhadap rasa nyeri yang dialami serta responden menjadi lebih nyaman dalam proses persalinannya.

Metode jarik shake the apple tree efektif dalam peningkatan pengetahuan persepsi nyeri persalinan dengan adanya dukungan dari pendamping persalinan dari keluarga dan dukunganpersalinan oleh petugas kesehatan sebelum dan sesudah intervensi.

\section{Kesimpulan dan Saran}

Disarankan bagi ibu bersalin dapat menggunakan teknik jarik shaking the apple tree saat kontraksi berlangsung sebagai salah satu metode penanganan nyeri pada persalinan dan bagi peneliti selanjutnya dapat melakukan penelitian lanjutan dengan efektifitas shake the apple tree terhadap lama kala II

\section{Daftar Pustaka}

Akadri AA, O. O. (2018). Labour pain perception: experiences of Nigerian mothers. Pan Afr Med J. 2018 Aug, 23;30:288.

Aziato, L. A., \& Umoar, K. L. (2017). Labour Pain Experiences and Perceptions; a qualitative study among post-partum women in Ghana. BMC Pregnancy and Chilbirth, 1-14.

Indrayani, M. E. (2016). Asuhan Persalinan dan Bayi Baru Lahir. Jakarta: Trans Info Media.

Iversen, M. L., Midtgaard, J., Ekelin, M., \& Hegaard, H. K. (2017). Danish women's experiences of the rebozo technique during labour:. Sexual \& Reproductive Healthcare, 79-85. 
Kepahiang, D. K. (2018). Profile Kesehatan Kabupaten Kepahiang . Bengkulu: Dinas Kesehatan Kabupaten Kepahiang .

Kosasih, S. T. (2015). Konsep dan Aplikasi Relaksasi dalam Keperawatan Maternitas. Bandung : PT. Refika Aditama.

Maryunani, A. (2010). Nyeri dalam Persalinan"Teknik dan Cara Penanganan. Jakarta: CV. Trans Info Media.
Mousa, O., Abdelhafez, A. A., Abdelraheim, A. R., \& Yousef, A. M. (2018 ). Perceptions and Practice of Labor Pain-Relief Methods among Health Professionals Conducting Delivery in Minia Maternity Units in Egypt. Mousa, Ola et al. "Perceptions and Practice of Labor Pain-Relief Methods among Health Professionals Conducting DelObstetrics and gynecology international vol. 2018 3060953, 1-6.

Nurpratiwi, Y., Hadi , M., \& Idriani. (2020). Teknik RebozoTerhadap Intensitas Nyeri 